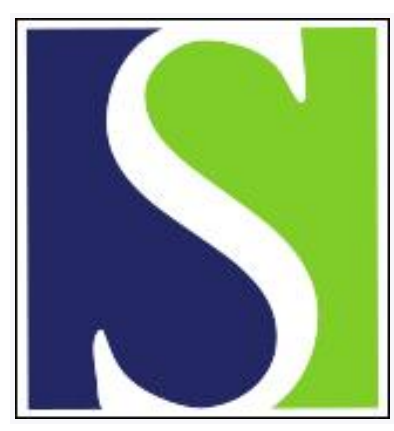

Scand J Work Environ Health 1996;22(1):39-44

https://doi.org/10.5271/sjweh.107

Issue date: Feb 1996

\title{
Exposure to high-frequency transient electromagnetic fields
}

by Skotte JH

Key terms: HFT field; high-frequency transient field; occupational environment; pulsed electromagnetic field; radio-telephone; residential environment; utility industry

This article in PubMed: www.ncbi.nlm.nih.gov/pubmed/8685672

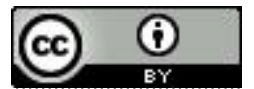




\title{
Exposure to high-frequency transient electromagnetic fields
}

\author{
by Jørgen H Skotte, MSc(Eng)t
}

Skotte JH. Exposure to high-frequency transient electromagnetic fields. Scand J Work Environ Health 1996; $22: 39-44$

Objectives The purpose of this study was to assess exposure to high-frequency transient (HFT) electromagnetic fields in occupational and residential environments.

Methods Exposure to HFT electromagnetic fields was measured with personal dosimeters for 301 volunteers (396 measurements) in periods of $24 \mathrm{~h}$ in both occupational and residential environments. The study included electrical utility workers (generation, transmission, distribution, substation), office and industrial workers, and people living near high-power transmission lines. The measure of exposure to HFT fields was specified as the proportion of time (parts per million) in which the electric field exceeds a nominal threshold level of $200 \mathrm{~V} \cdot \mathrm{m}^{-1}$ at 5-20 MHz. Recently the specification of the HFT channel of the dosimeter has been found to be incomplete; therefore a testing of the threshold level and the sensitivity to electromagnetic fields from radio-telephones was carried out.

Results The percentage of measurements with a mean workday exposure above $0.1 \mathrm{ppm}$ was $6.5-9.4 \%$ for the utility groups and $0.9 \%$ for all the nonwork measurements. It is likely that the use of radio-telephones has contributed significantly to the number of HFT events in some of the measurements, especially for the generation workers. The nominal threshold level of the dosimeter was found to vary considerably depending on the polarization of the field $\left(20-400 \mathrm{~V} \cdot \mathrm{m}^{-1}\right.$ at $13.56 \mathrm{MHz}$ for one instrument).

Conclusions Generally speaking, HFT fields appeared infrequently. The workday exposure to HFT fields and $50 \mathrm{~Hz}$ magnetic fields ranked the groups differently. There is a need for developing instrumentation for HFT field measurements further.

Key terms HFT fields, occupational, pulsed electromagnetic fields, radio-telephones, residential, utility industry.

Owing to the concern over a possible association between cancer and exposure to extremely low-frequency (ELF) electromagnetic fields, several measurement programs have been carried out to describe the occurrence of these fields in work and nonwork environments (14). Normally, exposures to power-frequency $(50 / 60 \mathrm{~Hz})$ magnetic or electric fields have been measured, but it has also been suggested that high-frequency transient (HFT) or pulsed electromagnetic fields might be of interest (5).

Chromosome aberrations have been found in the lymphocytes of high-voltage laboratory cable splicers exposed to complex electromagnetic fields consisting of static, alternating, or pulsed electric and magnetic fields and spark discharges (6). An association between exposure to HFT fields and the risk of developing lung cancer among Canadian electric utility workers has recently been reported (7). It has also been suggested that pulsed magnetic fields produce teratogenic effects in chicken embryos. Very few data on exposure to HFT fields have been published, and the current knowledge on the biological effects of HFT fields does not suggest which measures or parameters should be applied in the assessment of such fields.

HFT fields originate from switching operations in electrical circuits, for example, in electrical motors, power tools, circuit breakers, relays, and the like. HFT fields are characterized by very short-duration pulses (microseconds or less) containing a broad range of frequencies. An electrical discharge also generates transient fields.

This study reports on the results of HFT-field measurements in a survey including both occupational and residential exposures to $50 \mathrm{~Hz}$ electric and magnetic fields and HFT fields. The results on exposure to $50-\mathrm{Hz}$ fields have previously been reported (3).

\section{Subjects and methods}

\section{Subjects}

The study included electric utility workers, people living near high-power lines, office workers, industrial work-

1 National Institute of Occupational Health, Copenhagen, Denmark.

Reprint requests to: Mr J Skotte, Arbejdsmiljøinstituttet, Lersø Parkallé 105, DK-2100, Copenhagen, Denmark. 
ers, and others for a total of 301 subjects and 396 measurements. (Details can be found in reference 3.)

Electric utilities. Workers were selected from the following five primary work environments: generation facilities, transmission lines (voltage above or equal to 50 $\mathrm{kV}$ ), distribution lines (voltage less than $50 \mathrm{kV}$ ), substations, and other environments with electrical and nonelectrical jobs. The following job titles were represented: electricians, linesmen, cable splicers, facility operators, boilermen, smiths, engineers, mechanics, laborers, gardeners, surveyors, and others. The workers were employed in six different utility companies and four generation facilities.

Residences near high-power lines. Residences within 25-100 $\mathrm{m}$ from seven different types of high-power lines $(50 / 60 \mathrm{kV}, 132 / 150 \mathrm{kV}$, and $400 \mathrm{kV})$ were selected. This group also included some residences within $5 \mathrm{~m}$ of $132 \mathrm{kV}$ cables and residences near substation facilities.

Offices. The group working in an office environment included clerks, secretaries, managers, technical personnel, and others (all outside of the utility companies).

Industry I, high magnetic field exposure. A group of workers expected to have high exposure to $(50 \mathrm{~Hz})$ magnetic fields was selected. They were welders in a shipyard, electrical furnace workers and electricians in a steel mill plant, electrical furnace workers in a chemical plant, electric railroad engineers, and a laboratory technician working with a spectrophotometer.

Industry II, normal magnetic field exposure. A group of workers expected to have normal exposure to $(50 \mathrm{~Hz})$ magnetic fields was selected. They worked in an automobile repair shop, a plate shop, a machine shop, a laboratory, and a plant producing telecommunication equipment.

\section{Instrumentation}

Eight personal exposure meters (dosimeters) of the Positron model 378102 were used. The dosimeter measures $50 \mathrm{~Hz}$ magnetic and electric fields and HFT fields and shocks. According to the manufacturer's rather brief specifications, the dosimeter measures HFT fields with electrical field strengths above roughly $200 \mathrm{~V} \cdot \mathrm{m}^{-1}$ in the frequency range of 5-20 MHz. The dosimeter can be programmed to measure the field parameters in sample periods of 1,5 , or $60 \mathrm{~s}$. The HFT field-measuring channel consists of an internal wire antenna, a threshold detection circuit $\left(200 \mathrm{~V} \cdot \mathrm{m}^{-1}\right)$, an amplifier $(5-20$ $\mathrm{MHz}$ ), and a counter $(20 \mathrm{MHz})$. During the sample period the dosimeter continuously monitors the high-fre- quency electric field and counts the proportion of time in which the field strength exceeds $200 \mathrm{~V} \cdot \mathrm{m}^{-1}$. The unit of measurement was parts per million (ppm). For a 5-s sample period the detection level was $0.01 \mathrm{ppm}$, corresponding to a HFT field exceeding $200 \mathrm{~V} \cdot \mathrm{m}^{-1}$ during $0.05 \mu \mathrm{s}$. The meter quantifies and stores every measurement according to a 16-level classification scheme bin 1: $0-0.0008 \mathrm{ppm}$, bin 2: $0.0008-0.0033 \mathrm{ppm}$, bin 3: $0.0033-0.0133 \mathrm{ppm}, \ldots$, bin $15: 5.6-22.4 \%$, and bin 16: $22.4-100 \%$. The two lowest bins are not used for a 5-s sample period.

Recently, more details on the characteristics of the Positron's HFT channel have been published (8). It has been found that the frequency response is nonuniform with distinct resonances in the range $10-400 \mathrm{MHz}$ with peak sensitivities at 14,145 , and $300 \mathrm{MHz}$. The response is highly directional, and the threshold field strength is below $5-10 \mathrm{~V} \cdot \mathrm{m}^{-1}$ at the 145 and $300 \mathrm{MHz}$ resonances.

A short investigation was carried out in this study to check the characteristics of the HFT channel of the dosimeter. One Positron unit was placed in a $13.56 \mathrm{MHz}$ continuous electric field between to parallel plates, in which the field strength could be varied in the range 0 $600 \mathrm{~V} \cdot \mathrm{m}^{-1}$. The threshold field strength was found to vary in the range $20-400 \mathrm{~V} \cdot \mathrm{m}^{-1}$ (rms) depending on the orientation of the dosimeter in the electric field. The same unit was tested in a so-called TEM-cell (transverse electric and magnetic field transmission cell) capable of generating field strengths up to $150 \mathrm{~V} \cdot \mathrm{m}^{-1}$ for frequencies below $130 \mathrm{MHz}$. At $75 \mathrm{MHz}$ the threshold was found to be approximately $140 \mathrm{~V} \cdot \mathrm{m}^{-1}$ for the most sensitive polarization. These results are comparable with results reported by Guttman \& Young (8).

Examples of sources that have been found to be able to trigger the HFT channel of the Positron dosimeter are electric handtools and the switching on and off of motors, impulse generators used for cable-fault localization, and switching operations in substations $(8,9)$. During the testing of the Positron dosimeter in this study it was found that an ordinary cigarette lighter with electronic spark lighting was able to trigger the dosimeter within $5 \mathrm{~cm}$.

\section{Dosimeter sensitivity to radio communication equipment.} Because of the very low threshold level at some frequencies, the dosimeter has been found to be sensitive to electromagnetic fields within 5-10 m of car or truckmounted radio-telephones and to electromagnetic fields within roughly $1 \mathrm{~m}$ of handheld devices operating in the frequency range of $140-160 \mathrm{MHz}(8-10)$.

The utility companies in this study used various $25-\mathrm{W}$ vehicle-mounted VHF (75 $\mathrm{MHz}$ and $150 \mathrm{MHz})$ and $\mathrm{UHF}(450 \mathrm{MHz})$ radio-telephone systems and $5-\mathrm{W}$ handheld UHF (450 MHz) devices. The $75 \mathrm{MHz}$ and 
$450 \mathrm{MHz}$ systems were the most widespread; only one of the generation facilities used a $150 \mathrm{MHz}$ system. In the vehicles, the antenna was normally mounted on the roof and in some cars at the front fender. Cellular mobile telephones were not used in the utility companies at the time of the study (1991).

In order to estimate the influence of the use of radiocommunication equipment on the dosimeter data, several radio-telephones used by the utility companies were tested ( 6 truck-or car-mounted units and 2 handheld units). During continuous transmission most of the units could trigger the dosimeter within $20-30 \mathrm{~cm}$ of the antenna. When the transmitter was keyed to "on/off" the dosimeter could generally be triggered within $1-2 \mathrm{~m}$ of the antenna. A dosimeter worn in the belt responded to the use of a handheld $450-\mathrm{MHz}$ radio-telephone used by the wearer of the dosimeter himself or a person next to him if the transmitter was keyed to "on/off", but not during continuous transmission. By the truck-mounted radiotelephones the dosimeter often responded to "on/off" keying at positions just outside the front doors at a height above $1.5 \mathrm{~m}$. By some of the trucks, dosimeters worn in the belt responded to "on/off" keying of the radio-telephone at positions outside the front doors or on the door step. Inside trucks and cars with roof-mounted antennas no response was found in the areas of the driver's or helper's seat. However, inside a car with an antenna mounted on a front fender, a clear response was seen with the "on/off" keying of the transmitter. There were no clear differences in dosimeter response to $75-\mathrm{MHz}$ and $450-\mathrm{MHz}$ vehicle-mounted systems.

To conclude, both handheld and vehicle-mounted radio-telephones used by the utility companies were able to trigger the HFT channel of the Positron dosimeter when the transmitters were keyed to "on/off" within distances of $1-2 \mathrm{~m}$. The use of handheld devices seems more likely to influence the dosimeter than the typical use of vehicle-mounted transmitters.

\section{Measurement procedures}

The study consisted of 24-h measurements with a dosimeter sampling period of $5 \mathrm{~s}$. The dosimeter was normally worn in a leather case attached to a belt at the hip. In a few cases the dosimeter was carried in a trouser or shirt pocket. The display of the dosimeter was switched off during the measurement. The subjects wore the dosimeter at work, at home, during travel, and during other nonwork activities, and they recorded the times for these activities in a personal logbook.

Immediately after the measurement, the data were transmitted to a portable computer, after which the recordings - specially the $50-\mathrm{Hz}$ magnetic field recordings - were shown and explained to the subject. Less attention was paid to the HFT recording, but, if several or single high HFT events were found, the subjects were asked about their activities at the time when the HFT event(s) occurred. In a few cases the source of the HFT event could be identified.

According to the logbook, the dosimeter measurements were divided and analyzed into work and nonwork periods. Sleeping time was not included in the analysis. For some measurements a high HFT reading could be found in the very first 5-s sample period of the measurement. This was an erroneous response apparently related to the start of the dosimeter. The first sample period was not included in the analysis of these measurements.

\section{Results}

The exposures to HFT electromagnetic fields are shown in figure 1 and table 1. Figure 1 presents the distribution of the HFT events captured by the dosimeters for utility workers during work and nonwork (sleeping time excluded). The maximum number of events for a workday was 68 , obtained for a distribution cable splicer. This one measurement dominates the scores in bin 10 and 11 of the dosimeter for all utility workers in figure 1 . The average number of HFT events was 1.4 for the utility workers during a workday and 0.3 during the nonwork period.

In table 1 , results are shown for the work periods in the utility, office, industry I, and industry II groups and for the nonwork periods for people living in residences near power lines (power-line residence) and people living distant to power lines (no-line residence). "One measurement" equals a recording from the work or nonwork time of one subject. The cutpoint of 0.1 ppm was arbitrary, but it has been used elsewhere (7). The number of

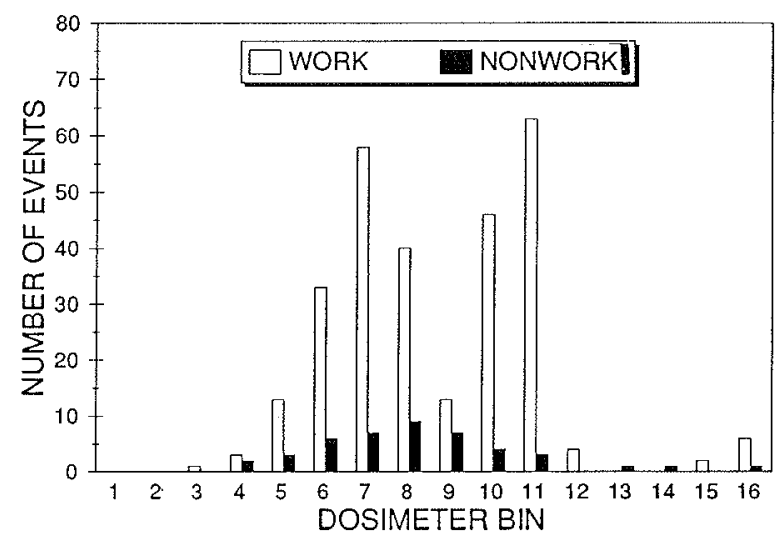

Figure 1. Distribution of high-frequency transient (HFT) events (number of triggered 5-s periods) captured by the Positron dosimeters for utility workers during work (282 events, 195 measurements, 1786 hours) and nonwork (44 events, 163 measurements, 1338 hours). The actual bin values in ppm (interval midpoint) can be calculated as $1.3 \cdot 10^{-4} \cdot 4^{\text {n }}$ $\mathrm{ppm}, \mathrm{n}=\mathrm{bin}$ number. For one utility worker (a distribution cable splicer) there were 68 events: 1 in bin 9,27 in bin 10,38 in bin 11, and 2 in bin 12. 
Table 1. Exposures to high frequency transient (HFT) electromagnetic fields during work and nonwork. $(95 \% \mathrm{Cl}=95 \%$ confidence interval)

\begin{tabular}{|c|c|c|c|c|c|c|c|c|}
\hline & \multirow{2}{*}{$\begin{array}{c}\text { Number } \\
\text { of } \\
\text { measurements }\end{array}$} & \multicolumn{2}{|c|}{$\begin{array}{l}\text { Measurements with } \\
\text { HFT events detected }\end{array}$} & \multicolumn{2}{|c|}{$\begin{array}{l}\text { Measurements with mean } \\
\mathrm{ppm} \text { value greater than } 0.1\end{array}$} & \multirow{2}{*}{$\begin{array}{l}\text { Maximum } \\
\text { ppm } \\
\text { value }\end{array}$} & \multicolumn{2}{|c|}{ Number of HFT events } \\
\hline & & $\%$ & $(95 \% \mathrm{Cl})$ & $\%$ & $(95 \% \mathrm{Cl})$ & & Mean & Maximum \\
\hline \multicolumn{9}{|l|}{ Work } \\
\hline Utility & 195 & 25.1 & $19.2-31.8$ & 7.2 & $4.0-11.4$ & 390 & 1.4 & 68 \\
\hline $\begin{array}{l}\text { Generation } \\
\text { Transmission } \\
\text { Distribution } \\
\text { Substation } \\
\text { Other }\end{array}$ & $\begin{array}{l}64 \\
17 \\
51 \\
46 \\
17\end{array}$ & $\begin{array}{r}17.2 \\
11.8 \\
45.1 \\
26.1 \\
5.9\end{array}$ & $\begin{array}{r}8.9-28.7 \\
1.5-36.5 \\
31.2-59.7 \\
14.3-41.2 \\
0.1-28.7\end{array}$ & $\begin{array}{l}9.4 \\
5.9 \\
7.8 \\
6.5 \\
0.0\end{array}$ & $\begin{array}{l}3.5-19.3 \\
0.1-28.7 \\
2.2-19.0 \\
1.4-17.9 \\
0.0-19.5\end{array}$ & $\begin{array}{c}131 \\
0.11 \\
390 \\
0.36 \\
0.0015\end{array}$ & $\begin{array}{l}0.5 \\
0.1 \\
4.0 \\
0.9 \\
0.2\end{array}$ & $\begin{array}{r}8 \\
1 \\
68 \\
13 \\
3\end{array}$ \\
\hline $\begin{array}{l}\text { Office } \\
\text { Industry I } \\
\text { Industry II }\end{array}$ & $\begin{array}{l}83 \\
24 \\
30\end{array}$ & $\begin{array}{r}4.8 \\
16.7 \\
20.0\end{array}$ & $\begin{array}{l}1.3-11.8 \\
4.7-37.4 \\
7.7-38.5\end{array}$ & $\begin{array}{r}3.6 \\
12.5 \\
0.0\end{array}$ & $\begin{array}{l}0.8-10.3 \\
2.7-32.2 \\
0.0-11.6\end{array}$ & $\begin{array}{r}85 \\
148 \\
0.0008\end{array}$ & $\begin{array}{l}0.1 \\
0.8 \\
0.5\end{array}$ & $\begin{array}{r}2 \\
13 \\
8\end{array}$ \\
\hline \multicolumn{9}{|l|}{ Nonwork } \\
\hline $\begin{array}{l}\text { Power-line residence } \\
\text { No-line residence }\end{array}$ & $\begin{array}{r}51 \\
295\end{array}$ & $\begin{array}{l}15.7 \\
11.5\end{array}$ & $\begin{array}{l}5.0-28.6 \\
8.0-15.6\end{array}$ & $\begin{array}{l}0.0 \\
1.0\end{array}$ & $\begin{array}{l}0.0-7.0 \\
0.2-3.0\end{array}$ & $\begin{array}{l}0.041 \\
80\end{array}$ & $\begin{array}{l}0.4 \\
0.3\end{array}$ & $\begin{array}{l}7 \\
5\end{array}$ \\
\hline All nonwork & 346 & 12.1 & $8.8-15.9$ & 0.9 & $0.2-2.5$ & 80 & 0.3 & 7 \\
\hline
\end{tabular}

HFT events in a measurement means the number of 5-s sample periods in which an HFT event occurred.

The no-line residence group consists of measurements in the non-work periods for all the utility, office, and industry workers. The mean measurement time was $8.6 \mathrm{~h}$ for the work periods. For the nonwork periods it was $8.1 \mathrm{~h}$ for the no-line residence group and $11.6 \mathrm{~h}$ for the power-line residence group. The measurement time was longer in this group because the group included measurements on days off and measurements for pensioners and unemployed persons who spent more time in their residence than the subjects in the other groups, who were all gainfully employed.

In all the groups apart from that of the distribution workers, HFT events were found in less than $26 \%$ of the measurements, and it was exceptional to find more than a few events during a full measurement period. In the utilities the measurements with HFT events were found for the following job categories: engineers, electricians, cable splicers, linesmen, workers, and others. In generation facilities the incidence of HFT events was highest among the engineers, approximately twice as high as in the other job categories.

The measurements in which HFT events occurred ranged from 5 to $45 \%$. The highest exposure was found for the distribution group (45\%), which had a significantly higher percentage than the other utility groups (chi-square test, $\mathrm{P}=0.0001$ ). This measure was also significantly higher $(\mathrm{P}=0.0001)$ for the utility group than for the office group and the corresponding measure during the nonwork periods.

The measurements with a mean ppm value greater than 0.1 ppm ranged between 0.0 and $12.5 \%$. This measure was significantly lower $(P \approx 0.0001)$ for the nonwork period than for the workday period in the utility group. There were no significant differences $(P=0.99)$ in these values between the distribution group and the other utility workers. This measure was higher for the industry I group than for the industry II group.

\section{Discussion}

On the whole HFT fields appeared infrequently. In most of the groups the percentage of measurements with a mean ppm value greater than $0.1 \mathrm{ppm}$ was low; therefore there was a risk that a few nontypical cases could dominate the exposure of that group. For example in the office group there were 83 measurements, and 3 of the 83 had a mean ppm value greater than $0.1 \mathrm{ppm}(3.6 \%)$. Therefore it cannot be ruled out that the HFT events, which caused the exposure, occurred in situations not normally associated with office work.

In the measurements for people living near power lines, the measurements with HFT events detected (15.7\%) was somewhat higher than for people living distant to power lines (11.5\%), but the measurement time was also somewhat longer in the near-line group (11.6 versus $8.1 \mathrm{~h}$ ); therefore this value would be likely to be proportionally higher too. There was no difference in the number of HFT events per hour (0.030) for these two groups. HFT fields of the order of several hundreds of volts per meter are mainly expected to be found very close to electric circuits and appliances, and, therefore, we did not expect to find any difference between these two groups either.

The measures of exposure to HFT fields do not generally rank the groups in the same way as the exposure to $50-\mathrm{Hz}$ magnetic fields previously found (3). The distribution workers had the highest number of measurements with HFT events detected but were found to have the 
lowest exposure to $50-\mathrm{Hz}$ magnetic fields when compared with the other utility workers. The substation workers, who were found to have the highest exposure to $50-\mathrm{Hz}$ magnetic fields, did not differ from the average utility worker with regard to the detection of HFT events or the number of measurements with a mean ppm value greater than $0.1 \mathrm{ppm}$. The industry I group, which was found to have the highest exposure to $50-\mathrm{Hz}$ magnetic fields, also had high exposure to levels with a mean ppm value greater than $0.1 \mathrm{ppm}$, but the exposure did not differ from the nonwork exposures with regard to the detection of HFT events. The values greater than $0.1 \mathrm{ppm}$ in the industry I group belonged to two electricians working in a steel mill plant and one shipyard welder. Both measures ranked nonwork lower than utility work, as was also found for $50-\mathrm{Hz}$ magnetic fields. The measurements for people living in residences near power lines, which were found to have high exposure to $50-\mathrm{Hz}$ magnetic fields, showed no differences in exposure to HFT fields.

Details on the specific task at the time that the HFT event occurred were only available in a few cases. For a cable splicer with a mean workday exposure of $0.39 \mathrm{ppm}$, the HFT events occurred during high-voltage testing of cables. For one subject the use of an electric handtool was being recorded at the time of an HFT event. For another worker a welding operation was being recorded; however welding did not generally appear to be a source of HFT events.

An electrician working in a generation facility reported on the use of a handheld radio-telephone just at the time of a HFT event causing a mean workday exposure of $131 \mathrm{ppm}$, which was one of the highest HFT recordings. Handheld radio-telephones were in general use in at least two (of 4) of the generation facilities, specially among engineers, who also had the highest incidence of HFT measurements in the generator facilities. As our tests have shown that radio-telephones are able to trigger dosimeters, it seems likely that the use of handheld radio-telephones has contributed significantly to the number of HFT measurements in the generator environment. Workers in the transmission, distribution, and substation groups did not normally have handheld radio-telephones at their disposal, but many of them occasionally used vehicle-mounted units. It is estimated that several workers wearing the dosimeters could have used a vehicle-mounted radio-telephone, for example, a few times a day, and this use could trigger the dosimeter. The tests showed, however, that a radio-telephone with an external antenna could not trigger the dosimeter inside a truck, therefore much radio communication could have been carried out without the dosimeter being triggered. Thus it is not possible to estimate closely the influence of the use of radio-telephones on HFT recordings. It is likely that the use of radio-telephones was a significant source to HFT events in the generation group, but the HFT recordings of the utility workers were probably not dominated by this source.

Exposure to HFT fields measured with Positron dosimeters in the utility industry in Canada and France has been reported in one study (7). In Canada measurements with ppm values greater than $0.1 \mathrm{ppm}$ varied between 23 and $82 \%$, whereas in France the range was 0 $16 \%$ (significantly lower) for groups of generation, transmission, distribution, and substation workers measured during one week. In our study the results for the similar groups of utility workers ranged between 6 and $10 \%$, which is at the same level as reported in France. It should be noted, however, that the measurement period (1 day) was shorter in this study, and this difference might have had an influence on the variations in the measurement results.

This study and other tests have shown that the response of the HFT channel of the Positron dosimeter has some shortcomings and modifications of frequency response and threshold level would be appropriate. It has also been proposed that the dosimeter could be redesigned to take advantage of the infrequent occurrence of HFT events so that it would be possible to store more detailed characteristics of the few events in the memory of the instrument (9). The results of this study support this suggestion.

\section{References}

1. Merchant CJ, Renew DC, Swanson J. Occupational exposures to power-frequency magnetic fields in the electricity supply industry. J Radiol Prot 1994;14(2):155-64.

2. Sahl JD, Kelsh MA, Smith RW, Aseltine DA. Exposure to 60 $\mathrm{Hz}$ magnetic fields in the electric utility work environment. Bioelectromagnetics 1994;15:21-32.

3. Skotte JH. Exposure to power-frequency electromagnetic fields in Denmark. Scand J Work Environ Health 1994;20: 132-8.

4. Bracken TD. Exposure assessment for power frequency electric and magnetic fields. Am Ind Assoc J 1993;54(4):165-77.

5. Héroux P. A dosimeter for assessment of exposures to ELF fields. Bioelectromagnetics 1991;12:241-57.

6. Skyberg K, Hansteen IL, Vistnes AI. Chromosome aberrations in lymphocytes of high-voltage laboratory cable splicers exposed to electromagnetic fields. Scand J Work Environ Health 1993;19:29-34.

7. Armstrong B, Thériault G, Guénel P, Deadman J, Goldberg M, Héroux P. Association between exposure to pulsed electromagnetic fields and cancer in electric utility workers in Quebec, Canada, and France. Am J Epidemiol 1994; 140(9):80520.

8. Guttman JL, Young FS. Frequency response characterization of the Positron electromagnetic dosimeter pulsed electromagnetic field/high-frequency transient electric field channel. Campbell (CA): Enertech Consultants, 1994. Interim report RP 2966-07. 
9. Héroux P. Dielectric pulsed electro-magnetic fields detection using electromagnetic dosimeters. Poster presented at the 1994 annual review of research on biological effects of electric and magnetic fields from generation, delivery and use of electricity, Albuquerque, New Mexico, 7-10 November 1994.

10. Maruvada PS, Jutras P. Identification of sources responsible for utility worker exposure data obtained using Positron HFT channel. Varennes (Québec, Canada): Institut de recherche d'Hydro-Québec (IREQ), 1994. Report IREQ-94 -242C.

Received for publication: 20 March 1995 